\title{
Prevalence and associated risk factors of abnormal pap smear in pregnant women
}

\author{
Neha Mohindroo ${ }^{1}$, Anoop Sharma ${ }^{1 *}$, Santosh Minhas, ${ }^{2}$ Kushla Pathania ${ }^{1}$
}

\begin{abstract}
${ }^{1}$ Department of Obstetrics and Gynecology, Kamla Nehru Hospital for Mother and Child IGMCH Shimla, Himachal Pradesh, India

${ }^{2}$ Department of Obstetrics and Gynecology, MM Medical College and Hospital, Kumarhatti-Solan, Himachal Pradesh, India
\end{abstract}

Received: 30 September 2019

Accepted: 31 October 2019

\section{*Correspondence:}

Dr. Anoop Sharma,

E-mail: nehamohindroo@gmail.com

Copyright: (C) the author(s), publisher and licensee Medip Academy. This is an open-access article distributed under the terms of the Creative Commons Attribution Non-Commercial License, which permits unrestricted non-commercial use, distribution, and reproduction in any medium, provided the original work is properly cited.

\section{ABSTRACT}

Background: The Papanicolaou test is a method of cervical screening used to detect pre-cancerous and cancerous processes. The incidence of cervical cancer in India is alarmingly high and is the leading cause of cancer in women in India accounting for 147 deaths per lakh women. Cervical cytological abnormalities are found in up to $5 \%$ of all pregnancies. In Indian settings, published data on abnormal Pap smear in pregnancy is lacking. The present study was designed to know the prevalence of abnormal Pap smear in pregnant women and its associated risk factors.

Methods: This prospective study included 450 pregnant and 450 non pregnant women who fulfilled the inclusion criteria. After a detailed history, clinical examination and investigations, Pap smear was collected as per conventional method and reported using 2014 Bethesda system.

Results: $53.6 \%$ pregnant and 44.6\% non-pregnant subjects had abnormal Pap smear. Out of the abnormal smears in pregnant women, $31.18 \%$ had inflammatory cytology, $15.37 \%$ had bacterial vaginosis, $4.01 \%$ had Trichomonal and 3.34\% Monilial pathology. No epithelial cell abnormality was seen. Rural residence, lower class, age at first intercourse less than 21 years and having more than one sexual partner were important risk factors observed in our study and were statistically significant.

Conclusions: Bacterial vaginosis, the most common infection detected on Pap smear is strongly associated with previos preterm labour and delivery. This opportunity for screening of cervical cancer and counselling should not be missed in the antenatal period.

Keywords: Bacterial vaginosis, Cervical cancer screening, Pap smear, Pregnancy, Preterm labour

\section{INTRODUCTION}

The Papanicolaou test (abbreviated as Pap test) is a method of cervical screening used to detect potentially pre-cancerous and cancerous processes in the cervix. The Pap smear is the most successful cancer screening technique in history. It was named after its inventor, Dr. George Nicholas Papanicolaou. The incidence of cervical cancer in India is alarmingly high at 22-26.2 per lakh women and is the leading cause of cancer in women in our country accounting for 147 deaths per lakh women. ${ }^{1}$
The population at risk for the development of cervical cancer in India is 365.71 million women above the age of 15. Estimates indicate that in India, there are approximately 132,000 newly diagnosed cases each year and 74,000 deaths annually that is nearly $1 / 3^{\text {rd }}$ of the global cervical cancer deaths. ${ }^{2}$

Indian women face a $2.5 \%$ cumulative lifetime risk and $1.4 \%$ cumulative death risk from cervical cancer. ${ }^{2}$ 
Cervical cytological abnormalities are found in up to $5 \%$ of all pregnancies. ${ }^{3}$ Risk of invasive carcinoma ranges between $1-10 / 10,000$ pregnancies. $^{3}$ The majority of these cases are experienced in developing countries. In most Western countries, cytological screening is a standard part of antenatal protocols, but no such screening program exists in India.

Pap test detects $60-70 \%$ of cancer cervix. ${ }^{4}$ The accuracy of Pap smear in pregnancy is almost similar to that of non-pregnant women. Cervical intraepithelial neoplasia (CIN) is a premalignant lesion that may exist in one of three stages: CIN1, CIN2, or CIN3. CIN 1 which is usually due to infection. Cervical neoplasia is estimated to complicate 1.5 to 12 of every 100,000 pregnancies. $^{5}$ The peak age of incidence of pre-cancerous lesions of the cervix is in the age range of 25-35 years, and thus, antenatal subjects presents an opportunity for Pap smear examination in women who otherwise might not report for screening. 6

Apart from cervical neoplasia, Pap smear can detect vaginal infections. Reproductive tract infections in many cases are asymptomatic among women, making their detection and diagnosis difficult. Indeed, the experience of symptoms of vulvovaginitis during pregnancy depends on clinical, behavioural, and demographic factors. ${ }^{7}$ Numerous studies have shown an association between certain risk factors, dysplasia and cervical cancer which include gravidity, contraceptive use, age of coitarche, multiple partners, coexisting microbial infections, altered immune status, smoking and oral contraceptive use and in India, rural residence.

In Indian settings, published data on abnormal Pap smear in pregnancy is lacking. The present study was designed to know the prevalence of abnormal Pap smear in pregnant women and its effect on pregnancy at Kamla Nehru State Hospital for Mother and Child, IGMCH, Shimla, a tertiary care hospital in Himachal Pradesh, India.

\section{METHODS}

This prospective study was carried out in the department of Obstetrics and Gynaecology, Kamla Nehru State Hospital for Mother and Child, Indira Gandhi Medical College, Shimla, Himachal Pradesh from $1^{\text {st }}$ July 2016 to $31^{\text {st }}$ June 2017.

Taking a literature reported prevalence of $8 \%$ a sample size of minimum 450 women was necessary with a dropout rate of $10 \%$ according to the formula.

$\mathrm{N}=4 \mathrm{pq} / \mathrm{L} 2$

Where;

$\mathrm{p}=$ prevalence $\mathrm{q}=1-\mathrm{p}$

$\mathrm{L}=$ allowable absolute error

PAP smear was collected as per conventional method. Informed consent was obtained from women who fulfilled the inclusion criteria.

\section{Inclusion criteria}

- Pregnant women up to 16 weeks of gestation who came for 1 st antenatal check-up.

\section{Exclusion criteria}

- Per vaginum examination in the past 48 hours

- History of sexual intercourse in the past 48 hours

- History of vaginal douching in the past 48 hours

- History of vaginal medication in the past 48 hours

- Bleeding per vaginum.

The woman was placed in dorsal lithotomy position. After exposing the cervix using cusco's self-retaining speculum or Sim's bivalve speculum with an anterior vaginal wall retractor, speculum finding was noted, ectocervix sampled using an Ayer's spatula rotating 360 degrees and smearing on glass slides. It was immediately fixed with $95 \%$ ethyl alcohol, stained with papanicolaou stain and reported by the department of pathology, IGMC, Shimla by modified Bethesda Classification 2014.

A proforma containing general information on maternal age, parity, age at marriage, education, occupation, residence, socioeconomic status, contraception, sexual partners, smoking, HIV infection, warts and family history regarding cervical cancer was taken.

Those with abnormal tests were managed as per protocol. Results of cytology in pregnancy were compared with the consecutive non- pregnant group, age and duration of marriage matched.

\section{Statistical analysis}

Data was tabulated and statistically analysed by applying SPSS software to the abnormal Pap smear in pregnancy and to study the set aims.

\section{RESULTS}

A total of 900 patients were studied, 450 pregnant women (Group 1) and 450 non pregnant women (Group 2), who met the inclusion criteria. One smear was inadequate in the pregnant group while $15 / 450$ smears were inadequate in the non-pregnant group.

The prevalence of abnormal Pap smear in our pregnant population was $53.9 \%$ and in the non-pregnant population was $44.6 \%$ with the difference being statistically significant ( $\mathrm{p}$ value 0.005 ). 
Table 1: Distribution of smears according to cytology.

\begin{tabular}{|lllll|}
\hline Organisms & Pregnant group 1 & $(\mathrm{n=449)}$ & Non - Pregnant group 2 $(\mathbf{n = 4 3 5})$ \\
\hline Normal smear & Frequency & Percent & Frequency & Percent \\
\hline Inflammatory & 207 & $46.10 \%$ & 241 & $55.40 \%$ \\
\hline Bacterial vaginosis & 140 & $31.18 \%$ & 103 & $23.68 \%$ \\
\hline Trichomonas vaginalis & 69 & $15.37 \%$ & 57 & $13.10 \%$ \\
\hline Monilial & 19 & $4.01 \%$ & 14 & $3.22 \%$ \\
\hline
\end{tabular}

Table 2: Characteristics of subjects.

\begin{tabular}{|c|c|c|c|c|c|}
\hline \multirow[b]{3}{*}{ Characteristics } & \multicolumn{5}{|c|}{ Pap smear (n=449) } \\
\hline & \multicolumn{2}{|c|}{ Normal Pap smears $(n=207)$} & \multicolumn{3}{|c|}{ Abnormal Pap smears (n=242) } \\
\hline & Frequency & $\%$ & Frequency & $\%$ & P value \\
\hline Mean age in years & 25.66 years & & 25.06 years & & 0.395 \\
\hline Rural residence & 152 & $41.76 \%$ & 212 & $58.24 \%$ & \multirow{2}{*}{0.001} \\
\hline Urban residence & 55 & $64.71 \%$ & 30 & $35.29 \%$ & \\
\hline Age of coitarche $<21$ years & 21 & $12.14 \%$ & 152 & $87.86 \%$ & \multirow{2}{*}{0.001} \\
\hline Age of coitarche $\geq 21$ years & 186 & $67.39 \%$ & 90 & $32.61 \%$ & \\
\hline No of sexual partners -1 & 203 & $47.10 \%$ & 228 & $52.90 \%$ & \multirow{2}{*}{0.038} \\
\hline No of sexual partners > 1 & 4 & $22.22 \%$ & 14 & $77.78 \%$ & \\
\hline $\mathrm{OCP}$ & 19 & $55.88 \%$ & 15 & $44.12 \%$ & 0.234 \\
\hline Copper T & 1 & $9.09 \%$ & 10 & $90.91 \%$ & 0.01 \\
\hline Primigravida & 125 & $63.45 \%$ & 72 & $36.55 \%$ & \multirow{2}{*}{0.06} \\
\hline Multigravida & 82 & $32.54 \%$ & 170 & $67.46 \%$ & \\
\hline Previous abortions-No & 193 & $47.77 \%$ & 211 & $52.23 \%$ & \multirow{2}{*}{0.04} \\
\hline Previous abortions-Yes & 14 & $31.11 \%$ & 31 & $68.89 \%$ & \\
\hline Previous preterm -No & 199 & $47.27 \%$ & 222 & $52.73 \%$ & \multirow{2}{*}{0.05} \\
\hline Previous preterm- Yes & 8 & $28.57 \%$ & 20 & $71.43 \%$ & \\
\hline History of genital warts- No & 207 & $46.31 \%$ & 240 & $53.69 \%$ & \multirow{2}{*}{0.19} \\
\hline History of genital warts Yes & 0 & $0.00 \%$ & 2 & $100.00 \%$ & \\
\hline Smoker -No & 206 & $46.29 \%$ & 239 & $53.71 \%$ & \multirow{2}{*}{0.06} \\
\hline Smoker -Yes & 1 & $25.00 \%$ & 3 & $75.00 \%$ & \\
\hline Per speculum cervix -Healthy & 201 & $52.76 \%$ & 180 & $47.24 \%$ & \multirow{2}{*}{0.001} \\
\hline Per speculum cervix-Unhealthy & 6 & $8.82 \%$ & 62 & $91.18 \%$ & \\
\hline
\end{tabular}

It was observed in Group 1 that 242 smears were abnormal on examination. Out of these, $140(31.18 \%)$ women had inflammatory smears, $69(15.37 \%)$ had bacterial vaginosis while $19(4.01 \%)$ and 15 (3.34\%) had Trichomonal and Monilial pathology respectively (Table $1)$.

In Group 2 it was observed that 194 smears were abnormal on examination. Out of these, $103(23.68 \%)$ women had inflammatory smears, $57(13.10 \%)$ had bacterial vaginosis and Trichomonal and Monilial pathology were seen in $14(3.22 \%)$ and $20(4.60 \%)$ subjects respectively.

There is no difference in maternal age, use of oral contraceptive pills, gravidity of the subject, history of genital warts and smoking. However, there was statistical difference noted in risk factors which included residence (rural and urban), age less than 21 years at coitarche, more than one sexual partner, use of copper $\mathrm{T}$, history of previous abortions and preterm birth and unhealthy cervix on per speculum examination (Table 2).

The odds of having an abnormal Pap smear are more in lower middle, upper lower and lower class and more in illiterate population.

\section{DISCUSSION}

In the present study, the abnormal smears indicative of inflammatory smears, bacterial vaginosis, candida infection and Trichomonas vaginalis were $31.18 \%$, $15.37 \%, 3.34 \%$ and $4.01 \%$ respectively, whose significance has been a matter of much interest in relation to pregnancy complications. However, in the present study no epithelial cell abnormality was detected. The 
maximum abnormal pap smears were seen in age group of 21-35 years which accounted for $96.21 \%$ of abnormal smears. It was further observed that mean age was similar in normal as well as abnormal Pap smears. As in Himachal Pradesh mean age for marriage is 21.9 years (District Level Household and facility Survey-3, 20072008) and there is early child bearing, hence mean age of women is less in our study. ${ }^{8}$

The urban-rural difference between the normal and abnormal smears was statistically significant $(\mathrm{p}=0.001)$. This was in accordance with the study by Shretha et al and Arora et al. ${ }^{9,10}$ Screening programs need to be intensified in rural areas, where there is less access to the medical services, lower levels of education, less awareness of preventive measures and an early age at marriage.

A total of $61.5 \%$ were 21 years or older at first intercourse compared to $38.5 \%$ who were younger than 21 years at first intercourse. The difference between age at first intercourse between normal and abnormal smears was significant $(\mathrm{p}=0.001)$. Age at first intercourse was a risk factor for our study but no epithelial cell abnormality was seen. This was in accordance with the latest guidelines laid down by the American Cancer Society which advocate beginning of Pap smear screening of women at the age of 21 , regardless of sexual activity. Mannikam et al, found a similar relation between abnormal smears in pregnant women and early age at first intercourse. $^{11}$

There was a statistically significant correlation between having more than one sexual partner and an abnormal smear $(p=0.038)$. In our study the percentage of subjects who used barrier method as a contraceptive measure was $20.6 \%, 7.5 \%$ used oral contraceptive pills and $2.5 \%$ used IUCD. The statistical difference was not significant in OCPs users while was statistically significant in IUCD users. Use of barrier contraception for protection against sexually transmitted diseases is well proven, which includes HPV infection. OCP intake in our subjects was for a minimum of 6 months to a maximum of 4 years and was not associated with increased risk of abnormal smears in this study. Mannikam et al shows a higher percentage of subjects not using any contraception. Ajah LO et al, also showed no statistically significant difference in abnormal cervical epithelial cytology between the participants on hormonal contraceptives and nonusers of modern contraception. This contradicts much of literature which shows a significant relation between OCP use and cervical neoplasia. Only long-term use of OCPs increases the risk of cervical cancer and the changes caused by OCPs revert to never users after 10 years or more. This suggests that hormonal contraceptives may not increase the risk of cervical neoplasia. There is a need to conduct a cohort study on this topic in our environment, to further strengthen or refute the safety of hormonal contraceptives. ${ }^{11,12}$ There was statistical significance between gravidity and abnormal smears and it was a risk factor in this study. Bijeta et al, Himabindu et al, Manikkam et al and Prabhu TRB, also reported higher number of smears in the multiparous group. Screening should take place regardless of gravidity and the first pregnancy is ideal for a first Pap smear in an area with no comprehensive screening programme. , $^{41,13,14}$

The percentage of smokers in our population was $0.9 \%$. The proposed reason for this disparity could be that women in the studied population smoke less or were not forthcoming in history. The relationship between smokers and abnormal smears was not significant $(p=0.06)$. This was not in accordance with the study compared above, which shows a link between smoking and abnormal cervical smears. The proposed mechanism is that smoking decreasing immune resistance and the ability of the immune system to clear the body of infections.

The correlation of abnormal smears to an unhealthy cervix is significant $(p=0.0007)$ which is similar to a study conducted by Himabindhu et al. ${ }^{4}$ An unhealthy cervix per speculum is highly suggestive of cervical pathology and is an independent risk factor for an abnormal Pap smear.

\section{CONCLUSION}

Very little data is available in India in regard to the role of Pap smear in pregnancy. The present study was an attempt to determine the prevalence and the associated risk factors of abnormal Pap smear in pregnant women. Pap smear screening should be done in all antenatal women as a routine screening program. Visits for antenatal check-ups by women are a potential opportunity to perform this test and educate them regarding the significance of screening. Cervical cancer can be detected at an early stage by Pap smear being a cost effective, easy to perform test and safe to be carried out even in pregnant woman without jeopardising the outcome. This opportunity for screening and counselling should not be missed. Education and spreading awareness is essential and such measures are in dire need. India suffers an undue burden from neoplastic cervical disease and great efforts must be made to decrease the morbidity and mortality from this preventable disease.

\section{Funding: No funding sources \\ Conflict of interest: None declared \\ Ethical approval: The study was approved by the Institutional Ethics Committee}

\section{REFERENCES}

1. National Centre for Disease Informatics Research. National Cancer Registry Programme, ICMR Three Year Report of Population Based Registries, 20092011. Available at: https://www.icmr. nic.in/sites/default/files/reports/Preliminary_Pages_ web.pdf. Accessed on $10^{\text {th }}$ August 2016. 
2. Summary report on HPV and cervical cancer statistics in India 2007.WHO/ICO Information Centre on HPV and Cervical Cancer. Available at: http://www.who.int/hpvcentre. Accessed on May $1^{\text {st }}$ 2008.

3. Morice P, Uzan C, Gouy S, Versharaegen C, HaieMeder C. Gynaecological cancers in pregnancy. Lancet. 2012;379:558-69.

4. Himabindu P, Kanwal A, Vasudha. Pap Smear In Antenatal Women - Routine Screening In Low Resource setting. Int Org Sci Res J Dent Med Sci (IOSR-JDMS). 2015;14(3):4-5.

5. Hunter MI. Monk BJ. Cervical neoplasia in pregnancy. Part 1: screening and management of preinvasive disease. Am J Obstet Gynaecol. 2008:38.

6. Ferenczy A, Franco E. Cervical-cancer screening beyond the year 2000. Lancet Oncol. 2012:27-32.

7. Nelson DB, Bellamy S, Nachamkin I, Ruffin A, Allen-Taylor L, Friedenberg FK. Characteristics and pregnancy outcomes of pregnant women asymptomatic for bacterial vaginosis. Matern Child Health J. 2008;12:216-22.

8. District level household and facility survey-3, Reproductive and Child Health Project, 2007-2008. Available at: http://rchiips.org/state-fact-sheetrch3.html. Accessed on $8^{\text {th }}$ August 2016.

9. Shrestha S, Tuladhar NR, Basnyat S, Acharya GP, Shrestha P, Kumar P. Prevalence of vaginitis among pregnant women attending Paropakar Maternity and
Women's Hospital, Thapathali, Kathmandu, Nepal. Nepal Med Coll J. 2011;13:293-6.

10. Arora BB, Maheshwari M, Devgan N, Arora DR. Prevalence of trichomoniasis, vaginal candidiasis, genital herpes, chlamydiasis, and actinomycosis among urban and rural women of Haryana, India. J Sex Transm Dis.2014;2014:963812.

11. Manikkam B. Screening for cervical cancer during pregnancy. Int J Community Med Public Health. 2016;3(9):2493-8.

12. Ajah LO, Chigbu CO, Ozumba BC, Oguanuo TC, Ezeonu PO. Is there any association between hormonal contraceptives and cervical neoplasia in a poor Nigerian setting? Onco Targets Ther. 2015;9:1887-92.

13. Desai Veena A, Ragini V, Preet MP. Bacterial Vaginosis in patients with Idiopathic preterm labour. J Obstet Gynaecol India. 2009;59(1):53-7.

14. Prabhu TRB, Velayudham D, Nethaji S, Singhal H, Venkatachalam R. Opportunistic cervical cancer screening in pregnancy. Int $\mathrm{J}$ Med Res Health Sci. 2016;5(1):278-81.

Cite this article as: Mohindroo N, Sharma A, Minhas S, Pathania K. Prevalence and associated risk factors of abnormal pap smear in pregnant women. Int J Reprod Contracept Obstet Gynecol 2019;8:4980-4. 